\title{
EL DISCERNIMIENTO VOCACIONAL EN EL MAGISTERIO RECIENTE
}

DOI: https://doi.org/10.52039/seminarios.v59i207.271

\section{INTRODUCCIÓN}

El discernimiento vocacional es un apasionante misterio que nos adentra en lo más íntimo del inefable diálogo de amor entre Dios y el hombre. ¿Quién se atrevería a decir que puede conocer y explicar lo que sucede en el alma de quien es llamado por Dios? Sólo con profundo respeto y humildad podemos hablar de ello; sólo con piadoso temor, con sincera admiración, con fuerte conciencia de su carácter sagrado, podemos asomarnos a este excelso misterio.

Por eso, han de ser dadas gracias a Dios por poder hablar de esto, por poder pensar en ello. Darle gracias por la delicada y a la vez prodigiosa obra que es la vocación.

Si esto es así, ¿cómo puede, sin embargo, la Iglesia atreverse a establecer unos criterios objetivos para el discernimiento vocacional?

Trataré, pues, de exponer los criterios que podemos hallar en el Magisterio reciente. Es mi intención no limitarme a ofrecerles una simple información de algo que cualquiera puede fácilmente leer en una serie de documentos que están al alcance de la mano de todo el que disponga de una conexión a Internet. Me gustaría, y así voy a tratar de hacerlo, con la ayuda de Dios, invitarles a una reflexión sobre los temas de fondo que subyacen a estos criterios.

Podemos comenzar esta reflexión buscando una respuesta a la pregunta que acabo de formular: ¿cómo puede la Iglesia atreverse a dictaminar criterios de discernimiento vocacional? Como hemos visto, la pregunta emana de la consideración del carácter sagrado y personal -íntimo- de la vocación de todo hombre.

2. JUSTIFICACIÓN DE LA ENSEÑANZA DE LA IGLESIA SOBRE EL DISCERNIMIENTO VOCACIONAL

El beato Juan Pablo II ha advertido esta cuestión y nos ha dejado una respuesta a ella en el escrito más importante sobre la formación sacerdotal que ha salido de su pluma: la Exhortación apostólica postsinodal «Pastores Dabo Vobis», del año 1992.

Esta exhortación es el más importante de los documentos en los que el magisterio reciente ha abordado el tema de los criterios de discernimiento de la vo- 
cación sacerdotal. Los restantes documentos a los que debo referirme para exponer esta cuestión, principalmente algunas instrucciones de la Sagrada Congregación para la Educación Católica, en buena medida repiten los criterios de Juan Pablo II, citando textualmente pasajes clave de «Pastores dabo vobis» y añadiendo ciertos matices y concreciones sobre determinados asuntos particulares.

Pues bien, en el número 35 de «Pastores dabo vobis», Juan Pablo II justifica así la legitimidad de los criterios objetivos para el discernimiento vocacional: «Toda vocación cristiana viene de Dios, es don de Dios. Sin embargo, nunca se concede fuera o independientemente de la Iglesia, sino que siempre tiene lugar en la Iglesia y mediante ella»

Citando esta misma frase, se abre la instrucción sobre «Orientaciones para el uso de las competencias de la psicología en la admisión y en la formación de los candidatos al sacerdocio», firmada el 29 de junio de 2008 por la Congregación para la Educación Católica.

«La Iglesia -dice esta instrucción- tiene la tarea de discernir la vocación y la idoneidad de los candidatos al ministerio sacerdotal. En efecto, 'la llamada interior del Espíritu Santo tiene necesidad de ser reconocida por el Obispo como auténtica llamada'», concluye, citando de nuevo a Juan Pablo II en «Pastores dabo vobis».

Esta instrucción sobre el uso de las competencias de la psicología en la admisión y formación de los seminaristas, así como otras que citaré más adelante, son rubricadas por la autoridad de una congregación pontificia, pero están lógicamente aprobadas por el Santo Padre. En mi opinión, pueden considerarse verdadero magisterio pontificio del Papa Benedicto XVI, aunque él no las haya redactado directamente de su puño y letra, pues a fin de cuentas ha confiado a un determinado dicasterio el examen de alguna cuestión concreta y ha ratificado sus conclusiones autorizando la publicación del correspondiente documento.

Vemos, por tanto, que nuestro actual Papa está tan convencido como su predecesor de que el maravilloso misterio por el que Dios llama a un joven a ser sacerdote no sólo supone una rica experiencia subjetiva de diálogo personal de amor y libertad sino que también comporta unos elementos objetivos que dan cabida a una tarea de discernimiento a cargo de la Iglesia. Podríamos concluir afirmando que la dimensión eclesial de la vocación sacerdotal justifica la existencia de unos criterios objetivos de discernimiento vocacional.

La misma doctrina encontramos en otro documento de la Congregación para la Educación Católica, firmado el 4 de noviembre del año 2005, memoria de San Carlos Borromeo. Se trata de la «Instrucción sobre los criterios de discernimiento vocacional en relación con las personas de tendencias homosexuales», que en el número 3 explica: «Dos son los aspectos inseparables en toda vocación sacerdotal: el don gratuito de Dios y la libertad responsable del hombre. La vocación es un don de la gracia divina, recibido a través de la Iglesia, en la Iglesia y para el servicio de la Iglesia. Respondiendo a la llamada de Dios, el hombre se 
ofrece libremente a Él en el amor. El solo deseo de llegar a ser sacerdote no es suficiente y no existe un derecho a recibir la Sagrada Ordenación. Compete a la Iglesia, responsable de establecer los requisitos necesarios para la recepción de los Sacramentos instituidos por Cristo, discernir la idoneidad de quien desea entrar en el Seminario, acompañarlo durante los años de la formación y llamarlo a las Órdenes Sagradas, si lo juzga dotado de las cualidades requeridas.

Don de Dios y respuesta libre del individuo: he aquí los dos polos del misterio de la vocación, articulados en perfecta armonía y a su vez referidos a otra paradoja, la que une «diálogo personal» con «intervención de la Iglesia». El punto de unión que asegura el equilibrio: «La vocación es un don de la gracia divina, recibido a través de la Iglesia, en la Iglesia y para el servicio de la Iglesia».

-El discernimiento no es sólo negativo. «Es necesario que quien va a ordenarse goce de la debida libertad; está terminantemente prohibido obligar a alguien, de cualquier modo y por cualquier motivo, a recibir las órdenes, así como apartar de su recepción a uno que es canónicamente idóneo» (CIC, c. 1026). «Sólo por una causa canónica, aunque sea oculta, puede el Obispo propio o el Superior mayor competente prohibir a los diáconos destinados al presbiterado, súbditos suyos, la recepción de este orden, quedando a salvo el recurso conforme a derecho» (CIC, c. 1030).

-El discernimiento personal no queda sustituido. «Alentados por vuestros formadores, abrid vuestra alma a la luz del Señor para ver si este camino, que requiere valentía y autenticidad, es el vuestro, avanzando hacia el sacerdocio solamente si estáis firmemente persuadidos de que Dios os llama a ser sus ministros y plenamente decididos a ejercerlo obedeciendo las disposiciones de la Iglesia» (Homilía de Papa en el encuentro con los seminaristas, JMJ 2011).

\section{LA FORMACIÓN HUMANA}

El siguiente paso de nuestra reflexión será preguntarnos cuáles son esos criterios objetivos, o en otras palabras, cómo realiza la Iglesia esa tarea de discernimiento o en base a qué patrones de contraste ha de examinar a los candidatos al sacerdocio. Pues bien, los dos últimos papas, precisamente en los mismos dos documentos hasta ahora citados, ofrecen una respuesta también a esta interesante pregunta; respuesta que podríamos sintetizar con la fórmula la formación humana, fundamento de toda la formación sacerdotal. Se trata de una idea empeñadamente defendida por Juan Pablo II, especialmente en «Pastores dabo vobis» y ampliamente desarrollada en los números 43 y 44 de esta Exhortación, que la Instrucción de 2008 sobre el uso de las competencias de la psicología recoge casi literalmente.

Según ambos documentos, «el ministerio sacerdotal reclama unas cualidades, además de virtudes morales y teologales, que deben estar sostenidas por 
el equilibrio humano y psíquico, particularmente afectivo, de forma que permitan al sujeto estar predispuesto de manera adecuada a una donación de sí verdaderamente libre en la relación con los fieles, según una vida celibataria». Estas cualidades «van desde el equilibrio general de la personalidad, a la capacidad de llevar el peso de las responsabilidades pastorales, y desde el conocimiento profundo del alma humana al sentido de la justicia y de la lealtad».

El don de sí mismo, exigencia de la identificación con Cristo: PDV 21-23.

«Sólo deben ser ordenados aquellos que, según el juicio prudente del Obispo propio o del Superior mayor competente, sopesadas todas las circunstancias, tienen una fe íntegra, están movidos por recta intención, poseen la ciencia debida, gozan de buena fama y costumbres intachables, virtudes probadas y otras cualidades físicas y psíquicas congruentes con el orden que van a recibir» (CIC, c. 1029).

\section{LA MADUREZ AFECTIVA}

Congregación para la Educación Católica, Instrucción sobre los criterios de discernimiento vocacional en relación con las personas de tendencias homosexuales (4 de noviembre del año 2005), n. 3: «La formación del futuro sacerdote debe integrar, en una complementariedad esencial, las cuatro dimensiones de la formación: humana, espiritual, intelectual y pastoral. En ese contexto, se debe anotar la particular importancia de la formación humana, base necesaria de toda la formación. Para admitir a un candidato a la Ordenación diaconal, la Iglesia debe verificar, entre otras cosas, que haya sido alcanzada la madurez afectiva del candidato al sacerdocio».

La Instrucción sobre Orientaciones para el uso de las competencias de la psicología en la admisión y en la formación de los candidatos al sacerdocio», n. 2: «Algunas de estas cualidades merecen una particular atención: el sentido positivo y estable de la propia identidad viril y la capacidad de relacionarse de forma madura con otras personas o grupos de personas; un sólido sentido de pertenencia, fundamento de la futura comunión con el presbiterio y de una responsable colaboración con el ministerio del Obispo; la libertad de entusiasmarse por grandes ideales y la coherencia para realizarlos en la acción diaria; el valor de tomar decisiones y de permanecer fieles; el conocimiento de sí mismo, de las propias capacidades y límites, integrándolos en una buena estima de sí mismo ante Dios; la capacidad de corregirse; el gusto por la belleza, entendida como 'esplendor de la verdad', y el arte de reconocerla; la confianza que nace de la estima por el otro y que lleva a la acogida; la capacidad del candidato de integrar, según la visión cristiana, la propia sexualidad, también en consideración de la obligación del celibato».

Congregación para la Educación Católica, Instrucción sobre los criterios de discernimiento vocacional en relación con las personas de tendencias homo- 
sexuales (4 de noviembre de 2005), n. 2: «A la luz de tales enseñanzas ${ }^{1}$, este Dicasterio, de acuerdo con la Congregación para el Culto Divino y la Disciplina de los Sacramentos, cree necesario afirmar con claridad que la Iglesia, respetando profundamente a las personas en cuestión, no puede admitir al Seminario y a las Órdenes Sagradas a quienes practican la homosexualidad, presentan tendencias homosexuales profundamente arraigadas o sostienen la así llamada cultura gay.

Dichas personas se encuentran, efectivamente, en una situación que obstaculiza gravemente una correcta relación con hombres y mujeres. De ningún modo pueden ignorarse las consecuencias negativas que se pueden derivar de la Ordenación de personas con tendencias homosexuales profundamente arraigadas.

Si se tratase, en cambio, de tendencias homosexuales que fuesen sólo la expresión de un problema transitorio, como, por ejemplo, el de una adolescencia todavía no terminada, ésas deberán ser claramente superadas al menos tres años antes de la ordenación diaconal».

\section{CONCLUSIÓN}

La consideración de los criterios objetivos para el discernimiento vocacional nos adentra en una rica reflexión sobre la relación entre el orden natural y el sobrenatural: es la acción de la gracia divina en la naturaleza humana lo que aquí entra en juego.

Esto conlleva para los formadores y superiores competentes una clara exigencia de una serie de actitudes (humildad, espíritu de oración, mirada de fe, prudencia, etc.) además de una adecuada capacitación para comprender la naturaleza humana.

A pesar de lo delicado de su misión, es perfectamente posible llevarla a cumplimiento, siguiendo las indicaciones del Magisterio reciente de la Iglesia.

1. Las enseñanzas son: los actos son intrínsecamente inmorales y contrarios a la ley natural; la tendencia es desordenada. Fuentes: Sagrada Escritura, Catecismo de la Iglesia Católica, nn. 2357-2358 y diversos documentos de la Congregación para la Doctrina de la Fe: Declaración acerca de ciertas cuestiones de ética sexual 'Persona humana' (29 de diciembre de 1975); Carta sobre la atención pastoral a las personas homosexuales 'Homosexualitatis problema' (1 de octubre de 1986); Algunas consideraciones concernientes a la Respuesta a propuestas de ley sobre la no discriminación de las personas homosexuales (23 de julio de 1992); Consideraciones acerca de los proyectos de reconocimiento legal de las uniones entre personas homosexuales (3 de junio de 2003).

Homosexualitatis problema: «La particular inclinación de la persona homosexual, aunque no sea en sí un pecado, constituye sin embargo una tendencia, más o menos fuerte, hacia un comportamiento intrínsecamente malo desde el punto de vista moral. Por este motivo la inclinación misma debe ser considerada como objetivamente desordenada» (n. 3). 